\title{
Effect of strong-column weak-beam design provision on the seismic fragility of RC frame buildings
}

\author{
Mitesh Surana ${ }^{1} \cdot$ Yogendra Singh ${ }^{1} \cdot$ Dominik H. Lang ${ }^{2}$
}

Received: 1 April 2017 / Accepted: 30 March 2018 / Published online: 25 April 2018

(c) The Author(s) 2018

\begin{abstract}
Incremental dynamic analyses are conducted for a suite of low- and mid-rise reinforced-concrete special moment-resisting frame buildings. Buildings non-conforming and conforming to the strong-column weak-beam (SCWB) design criterion are considered. These buildings are designed for the two most severe seismic zones in India (i.e., zone IV and zone V) following the provisions of Indian Standards. It is observed that buildings non-conforming to the SCWB design criterion lead to an undesirable column failure collapse mechanism. Although yielding of columns cannot be avoided, even for buildings conforming to a SCWB ratio of 1.4, the observed collapse mechanism changes to a beam failure mechanism. This change in collapse mechanism leads to a significant increase in the building's global ductility capacity, and thereby in collapse capacity. The fragility analysis study of the considered buildings suggests that considering the SCWB design criterion leads to a significant reduction in collapse probability, particularly in the case of mid-rise buildings.
\end{abstract}

Keywords Capacity design $\cdot$ Collapse probability $\cdot$ Incremental dynamic analysis $\cdot$ RC moment-resisting frame buildings . Strong-column weak-beam design

\section{List of symbols}

$R \quad$ Response reduction factor

$T \quad$ Average period of vibration

$\beta_{\mathrm{M}} \quad$ Log-normal standard deviation representing modelling variability

$\beta_{\mathrm{RTR}} \quad$ Log-normal standard deviation representing recordto-record variability

$\beta_{\mathrm{T}} \quad$ Log-normal standard deviation representing total variability

$\mu_{\mathrm{T}} \quad$ Period-based ductility

$\Omega \quad$ Overstrength factor

$\rho \quad$ Redundancy factor

$\theta_{\mathrm{p}} \quad$ Pre-capping plastic rotation capacity

$\theta_{\mathrm{pc}} \quad$ Post-capping plastic rotation capacity

Yogendra Singh

yogendra.eq@gmail.com

Mitesh Surana

mitesh.bana@gmail.com

Dominik H. Lang

dominik@norsar.no

1 Department of Earthquake Engineering, Indian Institute of Technology Roorkee, Roorkee, India

2 Department of Earthquake Hazard and Risk, NORSAR, Kjeller, Norway

\section{Introduction}

At present, the seismic design codes of many countries all over the world (e.g., ASCE 7-10 2010; Eurocode 8 2004; IS 18932002 ) still follow a force-based design (FBD) approach which defines the target performance levels 'No Damage' and 'No Collapse' for a minor and major earthquake, respectively. The FBD methodology is based on prescriptions, in which the inelastic energy dissipation of the structures is accounted through a 'response reduction factor' $(R)$, often also referred to as 'behaviour factor'. This simplified ' $R$ ' factor is in generally dependent on a building's structural system, and considered to be strongly influenced by the building's ductility capacity $\left(\mu_{\mathrm{T}}\right)$. In addition, both structural overstrength $(\Omega)$ and redundancy $(\rho)$ are considered important contributors to the ' $R$ ' factor (NIST 2012).

The ductility capacity of a building $\mu_{\mathrm{T}}$ is strongly correlated with the failure mechanism which is in turn governed by the relative strength of the different members. Major international seismic design codes (i.e., ACI 318-14 2014; Eurocode 8 2004; IS 13920 2016) contain provisions for capacity design (strength hierarchy). One of the crucial provisions of capacity design for moment-resisting frames controls the relative strength of beams and columns, using a 'strong-column weak-beam (SCWB) ratio' (i.e., the ratio of 
the sum of nominal moment capacities of all columns to the sum of nominal flexural strengths of beams, framing into the same joint, in the direction under consideration).

A review of the major international seismic design code provisions (i.e., ACI 318-14 2014; Eurocode 8 2004; NZS 3101 2006; IS 13920 2016) reveals that significant variations exist in terms of the defined SCWB design requirements. ACI 318-14 (2014) suggests a SCWB ratio of 1.2, whereas Eurocode 8 (CEN 2004) suggests a factor of 1.3. A more stringent approach is adopted by New Zealand's code (NZS 3101 2006) with a SCWB ratio of 1.3. In addition, NZS 3101 also applies a dynamic magnification factor for the upper floors, as these are significantly affected by higher mode effects. The dynamic magnification factor varies with building period $(T)$ as well as along the height.

The previous Indian capacity design and detailing code IS 13920 (1993) does not suggest any factor to ensure the SCWB design, although it was mandatory to construct special moment-resisting frame (SMRF) buildings in seismic zones IV and V. Therefore, it is a general practice in the Indian design industry to design buildings without ensuring the SCWB design criterion. In the latest revision of the Indian capacity design and detailing code (IS 13920 2016), a SCWB ratio of 1.4 is recommended. This provision was declared mandatory for SMRF buildings in seismic zones IV and V.

Until now, only few studies (Dooley and Bracci 2001; Kuntz and Browning 2003; Ibarra and Krawinkler 2005; Haselton et al. 2011 and Cagurangan 2015) have been conducted in which the adequacy of SCWB design provision of seismic design codes is assessed. In the context of seismic design of new buildings, the influence of the SCWB ratio on the collapse performance of buildings has already been identified as a high-priority study (NIST 2012). Dooley and Bracci (2001) studied the response of 3- and 6-storied buildings with varying SCWB ratio from 0.80 to 2.40 and recommended a SCWB factor of 2 for satisfactory performance of reinforced-concrete (RC) frame buildings in general. Kuntz and Browning (2003) investigated the seismic response of 4to 16-storied buildings and suggested a location-dependent SCWB ratio along the height of the building. Ibarra and Krawinkler (2005) focused on 9- to 18-storied RC frame buildings and observed that, to avoid column hinging, a SCWB ratio as high as 3 is required. Haselton et al. (2011) studied the effect of SCWB ratio on the seismic performance and the inherent collapse probability of RC frame buildings. They observed that for a 4-storied building, a SCWB factor of 1.2 is adequate, whereas for a 12-storied building the building performance continues to improve up to a SCWB ratio of 3, and therefore, suggested a dependency of the SCWB ratio on the building height, too.

One of the major limitations of previous studies lies in the fact that all were conducted on two-dimensional models, subjected to uni-directional earthquake excitations. Further, none of the studies, except for the one by Haselton et al. (2011), examined adequacy of the existing code provisions on the SCWB ratio in terms of their effect on collapse probability. Consequently, there is no consensus about the values for the SCWB ratio for seismic design of RC frame buildings.

The main objective of the present study is to quantify the effect of the SCWB design criterion on the seismic fragility of RC frame buildings. Therefore, buildings with three different heights (2, 4 and 8 storeys) designed for two different seismic zones (i.e., zone IV and zone V) are considered. These buildings are designed non-conforming and conforming to SCWB design provisions of IS 13920 (1993) and IS 13920 (2016), respectively. Bi-directional incremental dynamic analyses (IDA) are conducted on 3D building models considering a general far-field ground-motion record suite recommended in FEMA P695 (2009). A total of 3279 nonlinear IDA are conducted on the considered building models. Further, comparisons of the observed collapse mechanisms, adjusted collapse margin ratios (CMR) and collapse fragilities are presented for the considered building models.

\section{Selection of building archetypes and design}

For the numerical studies, a representative generic building plan (Fig. 1) is chosen based on field surveys in the National Capital Region of India (DEQ 2009; Haldar 2013; Surana et al. 2018a). In the present study, 12 generic RC momentresisting frame buildings with different dimensions in the two principal building axes are considered. These models are representative for low- (2-storey and 4-storey), and mid-rise (8-storey) buildings prevalent in northern India. A string is assigned to each building model which identifies the building height, seismic zone and the corresponding SCWB design criterion as summarized in Table 1. For the considered building models, the storey height is kept constant to $3.3 \mathrm{~m}$, which is most commonly observed at multi-storey RC buildings in northern India (DEQ 2009; Haldar 2013; and Surana et al. 2018a).

The building models are generated in the integrated building analysis and design software ETABS 2016 (CSI 2016). Beams and columns are modelled using three-dimensional (3D) frame elements, while the slabs are defined as rigid diaphragms. The cracked section properties of both beams and columns are derived following ASCE 41-13 (2013) guidelines. Both dead and live loads are assigned to the building models according to IS 875 Part 1 (1987a) and IS 875 Part 2 (1987b), respectively. All the buildings are designed following the provisions of the relevant Indian standards (IS 456 2000; IS 1893 Part 1 2002; IS 1893 Part 1 2016; IS 


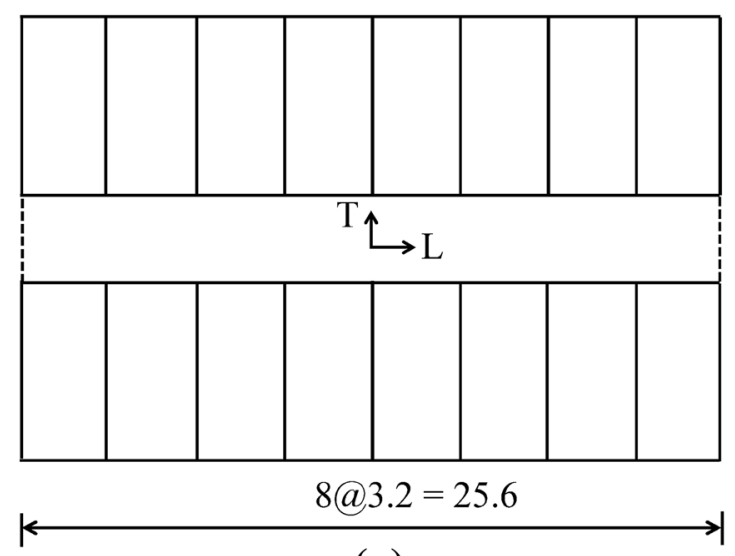

(a)

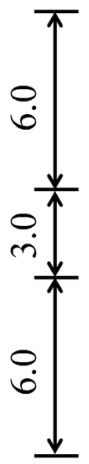

$\rightarrow$

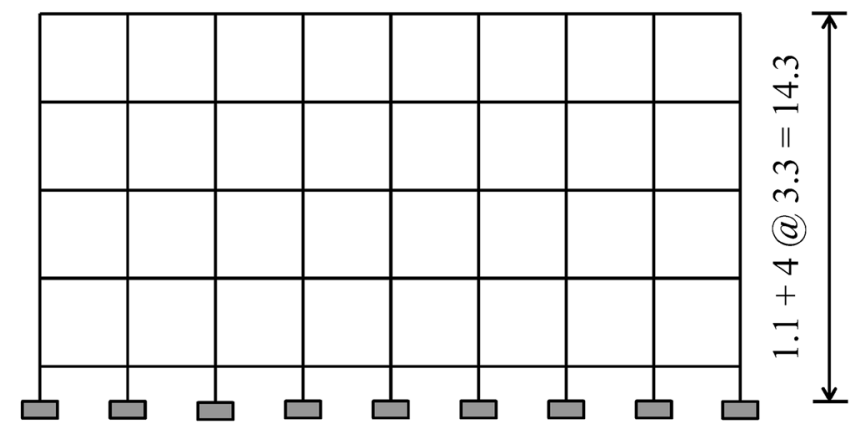

(b)

Fig. 1 Details of the generic building models chosen for the seismic fragility study: a Plan, and b Elevation of the 4-storey building model in longitudinal direction (elevations of the other building models are not presented here for the sake of brevity; $\mathrm{L}$ and $\mathrm{T}$ represent the

models' longitudinal and transverse direction, respectively; the dotted lines represent the boundaries of the floor slab). All dimensions are in meters
Table 1 Overview of the considered building models

\begin{tabular}{|c|c|c|c|c|c|}
\hline \multirow[t]{2}{*}{ Seismic zone } & \multirow[t]{2}{*}{ Design spectral parameter } & \multirow{2}{*}{$\begin{array}{l}\text { SCWB } \\
\text { requirements }\end{array}$} & \multicolumn{3}{|c|}{ Height class and corresponding string } \\
\hline & & & (2-storey) & (4-storey) & (8-storey) \\
\hline Zone IV & $\begin{array}{l}\mathrm{EPGA}_{\mathrm{MCE}}=0.24 \mathrm{~g} \\
S_{\mathrm{DS}}=0.45 \mathrm{~g} \\
S_{\mathrm{D} 1}=0.18 \mathrm{~g}\end{array}$ & $\mathrm{NC}$ & 2IVNC & $4 \mathrm{IVNC}$ & 8IVNC \\
\hline Zone V & $\begin{array}{l}\mathrm{EPGA}_{\mathrm{MCE}}=0.36 \mathrm{~g} \\
S_{\mathrm{DS}}=0.67 \mathrm{~g} \\
S_{\mathrm{D} 1}=0.27 \mathrm{~g}\end{array}$ & $\mathrm{NC}$ & $2 \mathrm{VNC}$ & $4 \mathrm{VNC}$ & $8 \mathrm{VNC}$ \\
\hline Zone IV & $\begin{array}{l}\mathrm{EPGA}_{\mathrm{MCE}}=0.24 \mathrm{~g} \\
S_{\mathrm{DS}}=0.45 \mathrm{~g} \\
S_{\mathrm{D} 1}=0.18 \mathrm{~g}\end{array}$ & $\mathrm{C}$ & 2IVC & $4 \mathrm{IVC}$ & $8 \mathrm{IVC}$ \\
\hline Zone V & $\begin{array}{l}\mathrm{EPGA}_{\mathrm{MCE}}=0.36 \mathrm{~g} \\
S_{\mathrm{DS}}=0.67 \mathrm{~g} \\
S_{\mathrm{D} 1}=0.27 \mathrm{~g}\end{array}$ & $\mathrm{C}$ & $2 \mathrm{VC}$ & $4 \mathrm{VC}$ & $8 \mathrm{VC}$ \\
\hline
\end{tabular}

$C$ conforming, $N C$ non-conforming
13920 1993; IS 13920 2016). Local subsoil conditions are represented by soil type I (i.e., hard soil/rock) following the soil classification defined by Indian code IS 1893 Part 1 (2016). P-delta effects are considered both in the design and structural analysis process.

Material strengths, periods of vibration (shown as arithmetic mean of the periods of vibration in the two principal directions of the building), design forces and obtained member sizes for the considered building models are summarized in Table 2. Member sizes are identical for both seismic zones and are chosen such that the reinforcement in columns is ranging from 1 to $3 \%$ and 2 to $4 \%$ for buildings designed for seismic zone IV and V, respectively, consistent with engineering practice in India. On the other hand, beam reinforcement is provided between 0.5 and $1.5 \%$ on each face, irrespective of seismic zone. In case of buildings non-conforming to the SCWB design criterion, the column reinforcement is derived from the design forces, while the SCWB ratio is identified as being close to 1.0; whereas in case of buildings conforming to the SCWB design criterion, the column reinforcement (obtained from design) is increased to achieve a SCWB ratio of 1.4. To compute the SCWB ratio, the nominal moment capacities for columns are computed at factored axial force consistent with the provision of IS 13920 (2016) and ACI 31814 (2014). The investigated building models have slightly higher SCWB ratios in the longitudinal direction as compared to the transverse direction, due to the shorter span of beams in the longitudinal direction. Further, this difference in SCWB ratio is higher in case of low-rise buildings designed for seismic zone IV, due to the increased effects of the gravity loads. 
Table 2 Details and member sizes of the considered building models

\begin{tabular}{|c|c|c|c|c|c|c|}
\hline \multirow[t]{2}{*}{ Building model } & \multicolumn{2}{|l|}{ Material strength } & \multirow{2}{*}{$\begin{array}{l}\text { Average period of } \\
\text { vibration }(\mathrm{s})^{\mathrm{a}}\end{array}$} & \multirow{2}{*}{$\begin{array}{l}\text { Design base shear } \\
\text { coefficient }(\mathrm{V} / \mathrm{W})\end{array}$} & \multirow[t]{2}{*}{ Column dimensions (mm) } & \multirow{2}{*}{$\begin{array}{l}\text { Beam } \\
\text { dimensions } \\
(\mathrm{mm})\end{array}$} \\
\hline & Concrete (MPa) & Rebars (MPa) & & & & \\
\hline 2IVNC & 40 & 500 & 1.00 & 0.090 & $350 \times 350$ & $300 \times 300$ \\
\hline 4IVNC & & & 1.50 & 0.065 & $350 \times 350$ & $300 \times 400$ \\
\hline 8IVNC & & & 3.35 & 0.040 & $300 \times 300 / 350 \times 350$ & $300 \times 400$ \\
\hline $2 \mathrm{VNC}$ & & & 1.00 & 0.060 & $350 \times 350$ & $300 \times 300$ \\
\hline $4 \mathrm{VNC}$ & & & 1.50 & 0.044 & $350 \times 350$ & $300 \times 400$ \\
\hline $8 \mathrm{VNC}$ & & & 3.35 & 0.027 & $300 \times 300 / 350 \times 350$ & $300 \times 400$ \\
\hline $2 \mathrm{IVC}$ & & & 1.00 & 0.090 & $350 \times 350$ & $300 \times 300$ \\
\hline 4IVC & & & 1.50 & 0.065 & $350 \times 350$ & $300 \times 400$ \\
\hline $8 \mathrm{IVC}$ & & & 3.35 & 0.040 & $300 \times 300 / 350 \times 350$ & $300 \times 400$ \\
\hline $2 \mathrm{VC}$ & & & 1.00 & 0.060 & $350 \times 350$ & $300 \times 300$ \\
\hline $4 \mathrm{VC}$ & & & 1.50 & 0.044 & $350 \times 350$ & $300 \times 400$ \\
\hline $8 \mathrm{VC}$ & & & 3.35 & 0.027 & $300 \times 300 / 350 \times 350$ & $300 \times 400$ \\
\hline
\end{tabular}

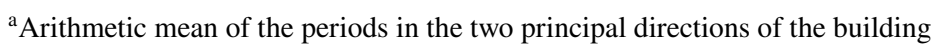

\section{Nonlinear modelling of building archetypes}

The nonlinear behaviour of RC frame members can be simulated using continuum, fiber, and lumped-plasticity models. The continuum and fiber models can accurately capture the effects such as cracking of concrete and yielding of reinforcement bars but they are unable to capture the strength degradation effects associated with reinforcement bar buckling, bond-slip and shear failure causing strain softening (Haselton et al. 2007, 2011). As these effects are more critical for the structural collapse assessment, the lumped-plasticity models have gained more popularity for seismic response simulation of RC buildings (Haselton and Deierlein 2007; PEER/ATC 72-1 2010; Haselton et al. 2011; Farsangi and Tasnimi 2016).

In lumped-plasticity models, the force-deformation behaviour of an element is confined by an envelope, known as the "backbone curve". This backbone curve has three most important parameters, namely the elastic stiffness, post-yield stiffness and post-capping stiffness (strain softening). The post-capping stiffness (softening) and the displacement (ductility capacity) at which this softening occurs, are the most important contributors affecting the seismic collapse capacity (Ibarra and Krawinkler 2005; Haselton et al. 2011; Farsangi and Tasnimi 2016). ASCE 41-13 (2013) provides the generic backbone curves for RC members having different reinforcement detailing, axial force and shear force. These backbone curves are based on cyclic test results and are primarily meant for design purposes, hence they are considered to be on the conservative side (PEER/ATC 72-1 2010; LATBSDC 2014). An alternative procedure based on the monotonic backbone curve has been suggested by Haselton et al. (2007) in which the cyclic degradation of stiffness and strength is considered in the hysteretic model.

In the present study, uniaxial moment plastic hinges and $\mathrm{P}-\mathrm{M}-\mathrm{M}$ interaction hinges have been assigned at both ends of beams and columns, respectively. These hinges are capable of simulating the side-sway collapse mechanism associated with RC SMRF buildings (FEMA P695 2009). The strength deterioration effects are inherently considered in the ASCE 41 backbone curves as these were obtained from the cyclic envelope (PEER/ATC 72-1 2010; LATBSDC 2014), whereas the degradation of stiffness and energy dissipation capacity is modelled explicitly using a peak-oriented degrading hysteresis model based on cumulative energy dissipation in ETABS 2016 (CSI 2016). This hysteresis model has been calibrated with experimental results obtained by Dadi and Agarwal (2015). Further details on calibration of the hysteresis model can be found in Surana et al. (2018b). ASCE 41 defines backbone curves in which strength drops suddenly post-capping. However, such sudden drops are highly unrealistic and cause numerical instability problems in the solution algorithm (PEER/ATC 72-1 2010; LATBSDC 2014). Therefore, a gradual reduction in strength as recommended in PEER/ATC 72-1 (2010) and FEMA P-58 (2012) is used for the estimation of collapse capacity of the building models. The typical backbone curve used in the present study is presented in Fig. 2 and the corresponding parameters are listed in Table 3.

\section{Incremental dynamic analysis}

To investigate the dynamic response of the considered structural models, incremental dynamic analyses (IDA) are conducted under bi-directional excitation (i.e., 


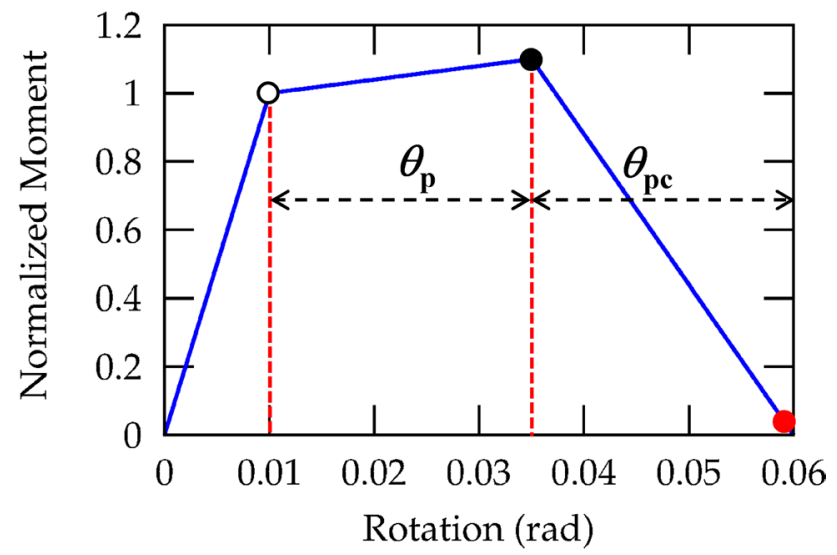

Fig. 2 Typical backbone curve for a RC beam

Table 3 Plastic rotation capacities of typical members

\begin{tabular}{llll}
\hline Member & $P / A_{\mathrm{g}} f_{\mathrm{c}}{ }^{\prime}$ & $\theta_{\mathrm{p}}$ & $\theta_{\mathrm{pc}}$ \\
\hline 2VC (beam) & 0.00 & 0.025 & 0.025 \\
4VC (beam) & 0.00 & 0.025 & 0.025 \\
8VC (beam) & 0.00 & 0.025 & 0.025 \\
2VC (column) & 0.06 & 0.027 & 0.007 \\
4VC (column) & 0.14 & 0.025 & 0.007 \\
8VC (column) & 0.19 & 0.020 & 0.005 \\
\hline
\end{tabular}

$\theta_{\mathrm{p}}$ and $\theta_{\mathrm{pc}}$ represent the pre-capping and post-capping plastic deformation capacities, respectively

simultaneous application of two horizontal components of the respective ground-motion record). The IDA consists of performing a series of dynamic analyses for a suite of selected earthquake ground-motion records, while each record is scaled in amplitude to capture the structural response from the elastic range to the point of dynamic instability (Vamvatsikos and Cornell 2002). It is considered as a very powerful tool for fragility analysis, as it enables the direct estimation of record-to-record (inter-event) variability in structural response. So far, various groups (Vamvatsikos and Cornell 2002; Haselton et al. 2011; Kazemi et al. 2013; Shakib and Pirizadeh 2014; Farsangi and Tasnimi 2016; Moniri 2017) have applied IDA to buildings of both regular and irregular configuration.

The selection of ground-motion records plays an important role for achieving reasonably accurate results with a limited number of analyses. In the present study, the farfield record suite (consisting of 22 pairs of ground-motion records) of FEMA P695 (2009) was considered, while $S_{\text {a }}$ $(T, 5 \%)$ was used as both the scaling parameter and intensity measure (IM). It is important to consider that the structural models investigated in the present study have different periods of vibration in the two principal directions of the building. Therefore, the arithmetic mean of the periods corresponding to the fundamental translational modes of the two orthogonal directions has been used for computing $S_{\text {a }}$ ( $T, 5 \%$ ) following the guidelines of FEMA P-58 (2012). To scale the bi-directional ground-motion records, the geometric mean of the spectral ordinates of individual components is used. Collapse is defined as the point where slight increments in the considered IM cause a large increase in damage measure (DM) (i.e., the maximum inter-storey drift ratio, representative of side-sway collapse). To model damping effects, a Rayleigh damping of 5\% is assigned at the periods corresponding to both the lowest mode and the mode resulting in a total of $95 \%$ cumulative mass participation.

\section{Dynamic capacity curves}

For the considered structural models, IDA are carried out using the FEMA P695 far-field ground-motion record suite. Figure 3 presents the dynamic capacity curves for the 8-storey building models designed for seismic zone $\mathrm{V}$, both nonconforming and conforming to the SCWB provision of IS 13920. The capacity curves are presented in terms of IM (i.e., $S_{\mathrm{a}}(T, 5 \%)$ ) versus DM (i.e., maximum inter-storey drift ratio) for individual records (44 curves obtained from a suite of 22 ground-motion records by interchanging two horizontal components along both principal axes), as well as the 16th, 50th (median), and 84th percentile dynamic capacity curves. Similar results are also obtained for other building models though not presented here for the sake of brevity.
Fig. 3 Dynamic capacity curves for the considered 8-storey building models designed for seismic zone V subjected to 22 pairs of far-field ground-motion records: a $8 \mathrm{VNC}$, and b $8 \mathrm{VC}$

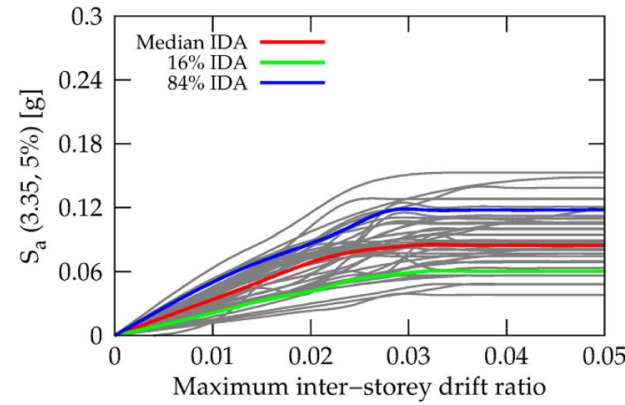

(a)

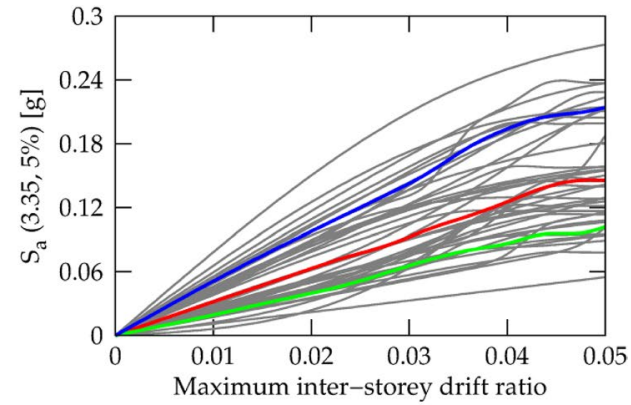

(b) 
It can be observed that both the 8-storey buildings (i.e., $8 \mathrm{VNC}$ and $8 \mathrm{VC}$ ) in seismic zone $\mathrm{V}$ are designed for the same base shear coefficient (Table 1), but the building model conforming to SCWB design requirement has a $77 \%$ higher collapse capacity as compared to the building model nonconforming to the SCWB design requirement. This effect is consistent among all building heights, although the increase in collapse capacity is somewhat lower (about 25-40\%) in case of low-rise (2- and 4-storey) buildings, mainly due to increased overstrength and gravity load effects (Table 4). This observation can be attributed to the fact that the building model non-conforming to the SCWB design requirement has a significantly different collapse mechanism (column failure mechanism defined as "columns of a single or multiple storeys reaching post-capping deformation capacity") as compared to the building model conforming to the SCWB design requirement (beam failure mechanism defined as "beams of a single or multiple storeys reaching post-capping deformation capacity").

\section{Comparison of collapse mechanisms for non-conforming and conforming buildings}

The collapse mechanisms for the 4- and 8-storey buildings (non-conforming as well as conforming to the SCWB design requirement) designed for seismic zone $\mathrm{V}$ are presented in Figs. 4 and 5, respectively. In the case of the 4-storey building non-conforming to the SCWB design requirements, collapse occurs due to failure of the columns of the first storey (Fig. 4). This column failure mechanism changes to beam failure in the case of the building conforming to the SCWB requirements (Fig. 4).
For the 8-storey buildings non-conforming to SCWB design requirements, two collapse mechanisms are observed. The first collapse mechanism consists of failure of columns in the first storey (Fig. 5). Whereas, in the second mechanism (not shown in the figure), failure of columns is also observed at the level of the fifth storey, where a change in column sizes along the height of the building takes place. This can be attributed to the combined effect of change in column sizes and a significant higher mode contribution. For buildings conforming to the SCWB criterion, the beam failure is observed at the levels of first, second, and third floors. In this case, damage is distributed over three storeys as compared to one storey in the case of the 4-storey building.

The observed trends have direct implications on the seismic design of buildings since the earlier discussed 'response reduction factor' (behaviour factor) strongly relies on the governing collapse mechanism. The herein presented results suggest that, even when designing for a SCWB ratio of 1.4 , column hinging (yielding) cannot be avoided. This is in good agreement with the previous studies (e.g. Dooley and Bracci 2001; Kuntz and Browning 2003) in which SCWB ratios of the order of 2 or even higher are suggested to avoid column yielding. However, failure is governed by failure of beams in one storey (in the case of low-rise buildings) and failure of beams in three storeys (in the case of mid-rise buildings). The observed trends clearly suggest that there is still room for possible improvement in the capacity design procedure to involve the beams of all the storeys in the failure mechanism. Kuntz and Browning (2003) suggested that a variable SCWB ratio along the height of the building would be needed to achieve a perfect beam sway mechanism. Such a failure mechanism is expected to further enhance the collapse capacity of the building. However, suggesting such a procedure to achieve simultaneous beam failure at all the storeys, is beyond the scope of the present study.
Table 4 Comparison of collapse margin ratios (CMR) for the considered building models

\begin{tabular}{lllllll}
\hline Building model & $S_{\mathrm{a}}(T)_{\text {Median }}(\mathrm{g})$ & SSF & CMR & ACMR & Acceptable ACMR & Performance \\
\hline 2IVNC & 0.66 & 1.08 & 2.75 & 3.56 & 1.66 & Pass \\
4IVNC & 0.44 & 1.15 & 2.75 & 3.80 & & Pass \\
8IVNC & 0.12 & 1.13 & 1.68 & 2.28 & & Pass \\
2VNC & 0.79 & 1.18 & 2.19 & 3.10 & & Pass \\
4VNC & 0.45 & 1.23 & 1.88 & 2.77 & Pass \\
8VNC & 0.09 & 1.08 & 0.84 & 1.09 & Fail \\
2IVC & 0.93 & 1.08 & 3.88 & 5.03 & & Pass \\
4IVC & 0.55 & 1.18 & 3.44 & 4.87 & & Pass \\
8IVC & 0.15 & 1.23 & 2.09 & 3.08 & & Pass \\
2VC & 0.99 & 1.13 & 2.75 & 3.73 & & Pass \\
4VC & 0.60 & 1.27 & 2.50 & 3.81 & & Pass \\
8VC & 0.16 & 1.20 & 1.49 & 2.15 & & \\
\hline
\end{tabular}


Fig. 4 Typical failure patterns for the considered 4-storey building models designed for seismic zone V subjected to 22 pairs of far-field ground-motion records: a $4 \mathrm{VNC}$ along longitudinal direction (observed for $91 \%$ ground-motion records), b $4 \mathrm{VNC}$ along transverse direction, $\mathbf{c} 4 \mathrm{VC}$ along longitudinal direction (observed for $84 \%$ ground-motion records), and $\mathbf{d}$ $4 \mathrm{VC}$ along transverse direction

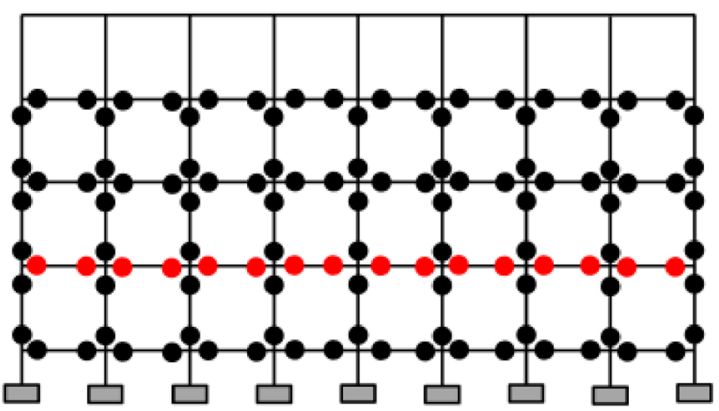

(c)
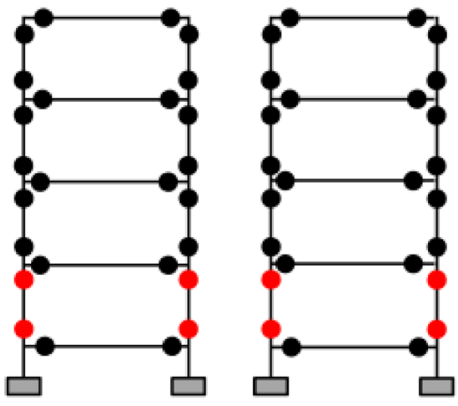

(b)
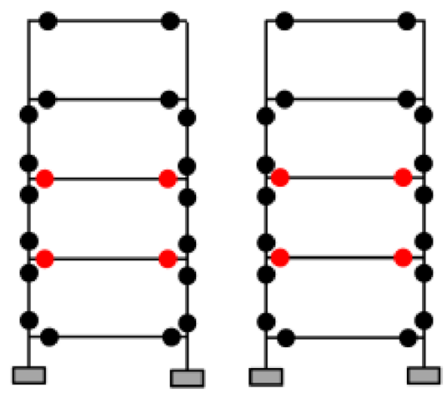

(d)

\section{Collapse performance evaluation}

To evaluate the collapse performance, the FEMA P695 (2009) methodology is utilized in the present study. The computation of a structure's median collapse capacity, its collapse margin ratio (CMR) [i.e., the ratio of the median collapse capacity of a building, $S_{\mathrm{a}}(T)_{\text {Median }}$, to the spectral acceleration demand corresponding to maximum considered earthquake (MCE), $S_{\mathrm{aMT}}(T, 5 \%)$ ], and its adjustment to spectral shape (frequency content) of the ground-motion records (Haselton and Deierlein 2007; Haselton et al. 2011; Kazemi et al. 2013; Farsangi and Tasnimi 2016) is an integral part of this methodology. In this study, the $S_{\mathrm{a}}(T)_{\text {Median }}$, and CMR are obtained from IDA, and the adjustment in collapse capacity for spectral shape effects is made using the spectral shape factor (SSF) recommended in FEMA P695 (2009).

The SSF value for each of the building models is dependent on the fundamental period $(T)$, the period-based ductility $\left(\mu_{\mathrm{T}}\right)$, and the seismic design category (FEMA P695 2009). The fundamental period $(T)$ and period-based ductility $\left(\mu_{\mathrm{T}}\right)$ are computed from Eigenvalue analysis and nonlinear static analysis, respectively. The FEMA P695 methodology is based on 2D building models with uni-directional earthquake excitation, whereas the present study is based on 3D building models with bi-directional excitations. Therefore, the arithmetic mean of the periods and the period-based ductility in the two orthogonal directions are used. FEMA
P695 also recommends increasing the estimated CMR using bi-directional analysis, by a factor of 1.2 for comparison with the specified acceptable limits. In the present study, the building models designed for seismic zone IV, have $S_{\mathrm{DS}}=0.45 \mathrm{~g}$ and $S_{\mathrm{D} 1}=0.18 \mathrm{~g}$, and the models designed for seismic zone V have $S_{\mathrm{DS}}=0.68 \mathrm{~g}$, and $S_{\mathrm{D} 1}=0.27 \mathrm{~g}$. These design spectral ordinates are equivalent to seismic design categories SDC $C$ and SDC $D_{\max }$ of FEMA P695, respectively. From the obtained arithmetic mean of the periods, period-based ductility, and seismic design category, the SSF is computed and collapse capacity is adjusted.

Table 4 presents a comparison of $S_{\mathrm{a}}(T)_{\text {Median }}$, and CMR. This CMR has been corrected for the effect of bi-directional analysis, and for the spectral shape of the ground-motion records using the SSF. Consequently, the adjusted CMR (ACMR) is obtained as ACMR $=1.2 \times \mathrm{CMR} \times \mathrm{SSF}$. ACMR is then compared with the acceptable CMR values recommended in FEMA P695, corresponding to a $20 \%$ probability of collapse conditioned on the occurrence of the MCE hazard. To obtain acceptable CMR values, a total system uncertainty of 0.60 is assumed (also justified later in this article). As observed from Table 4, all the considered models, except for $8 \mathrm{VNC}$, pass the performance criterion.

It can be observed that buildings in seismic zone $\mathrm{V}$ are designed for a $50 \%$ higher base shear coefficient (Table 1) when compared with their counterparts designed for seismic zone IV. However, the increase in median collapse capacity is in the range of $2-20 \%$ only. Buildings designed 
Fig. 5 Typical failure patterns for the considered 8-storey building models designed for seismic zone V subjected to 22 pairs of far-field ground-motion records: a $8 \mathrm{VNC}$ along longitudinal direction (observed for $61 \%$ ground-motion records), b $8 \mathrm{VNC}$ along transverse direction, $\mathbf{c} 8 \mathrm{VC}$ along longitudinal direction (observed for $82 \%$ ground-motion records), and $\mathbf{d}$ $8 \mathrm{VC}$ along transverse direction

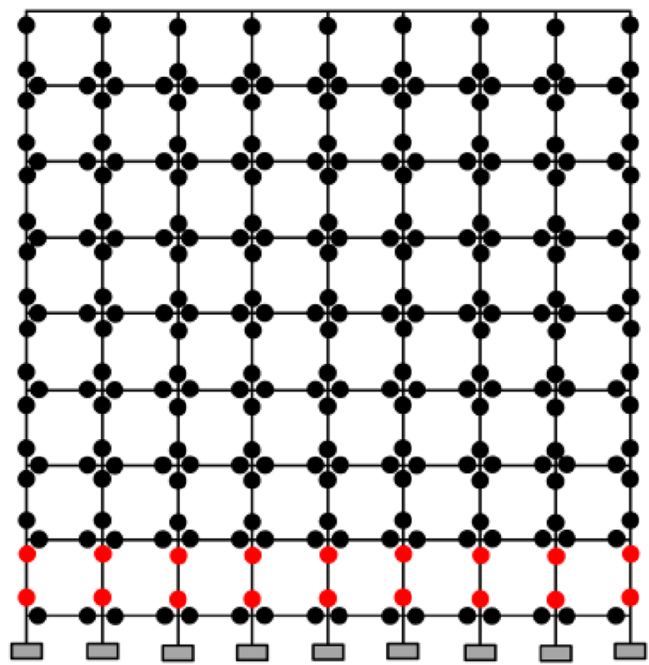

(a)

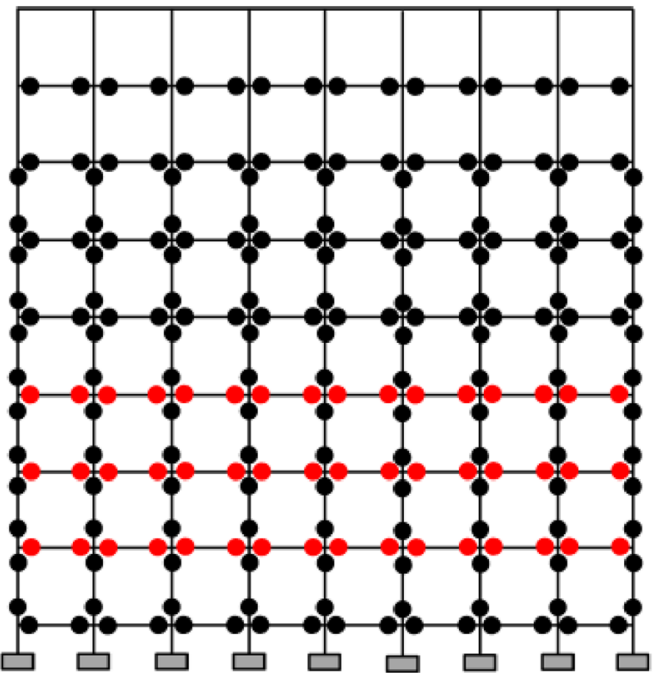

(c)
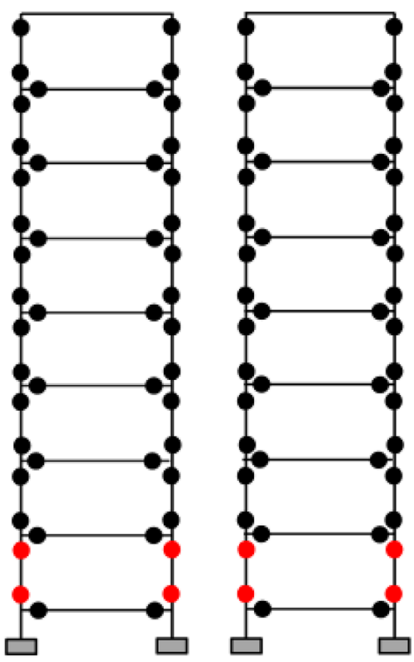

(b)
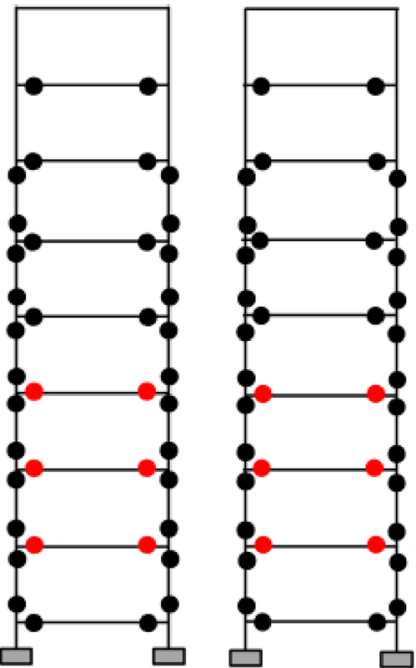

(d) conforming to the SCWB criterion have significantly higher ACMR (almost double in the case of the 8-storey building in seismic zone $\mathrm{V}$ ) as compared to buildings designed non-conforming to the SCWB criterion. Another salient observation from the table is, that the ACMR of buildings in seismic zone IV are 15-110\% higher when compared with the counterpart buildings in seismic zone $\mathrm{V}$. This can be attributed to the relatively increased effects of gravity loads for lower levels of seismic demands (i.e., seismic zone IV in the present study), which results in increased structural overstrength. Therefore, the same structural system designed for a lower seismic zone results in a higher margin against collapse for a specified level of seismic hazard (e.g., MCE). This observation is considered to be in good agreement with the FEMA P695 project work on 2D building models.

\section{Seismic fragility analysis}

The results obtained from IDA are post-processed following the methodology suggested by Haselton et al. (2011) to obtain fragility curves which are log-normal distributions obtained from median collapse capacity and its associated variability. The variability in collapse capacity has two components: (i) record-to-record variability $\left(\beta_{\mathrm{RTR}}\right)$, and (ii) modelling (epistemic) variability $\left(\beta_{\mathrm{M}}\right)$. The record-to-record variability $\left(\beta_{\mathrm{RTR}}\right)$ is obtained directly from the IDA results. Based on the study by Haselton and Deierlein (2007), Liel et al. (2009) showed that the modelling variability in the collapse fragility curves can be considered as 0.50 . Factors $\beta_{\mathrm{RTR}}$ and $\beta_{\mathrm{M}}$ are combined using the square-root-ofsum-of-squares (SRSS) method (Haselton et al. 2011; Liel et al. 2009) to obtain total variability $\left(\beta_{\mathrm{T}}\right)$. Table 5 presents 
Table 5 Record-to-record variability $\left(\beta_{\mathrm{RTR}}\right)$, modelling variability $\left(\beta_{\mathrm{M}}\right)$ and total variability $\left(\beta_{\mathrm{T}}\right)$ for the considered building models

\begin{tabular}{llll}
\hline Building model & $\beta_{\text {RTR }}$ & $\beta_{\mathrm{M}}$ & $\beta_{\mathrm{T}}$ \\
\hline 2IVNC & 0.28 & 0.50 & 0.57 \\
4IVNC & 0.30 & & 0.58 \\
8IVNC & 0.37 & & 0.62 \\
2VNC & 0.32 & & 0.59 \\
$4 \mathrm{VNC}$ & 0.30 & 0.58 \\
8VNC & 0.30 & 0.58 \\
2IVC & 0.28 & 0.57 \\
4IVC & 0.31 & 0.59 \\
8IVC & 0.31 & 0.59 \\
2VC & 0.26 & 0.56 \\
$4 \mathrm{VC}$ & 0.31 & 0.59 \\
$8 \mathrm{VC}$ & 0.32 & 0.59 \\
\hline
\end{tabular}

the different variability parameters for the building models investigated in the present study, while the corresponding fragility curves are shown in Fig. 6. It can be observed that, in case of all the investigated building models, the total variability $\left(\beta_{\mathrm{T}}\right)$ is close to 0.6 (which was assumed earlier while computing the acceptable CMR).

Table 6 presents the obtained collapse probabilities corresponding to the MCE hazard level for the investigated building models. The SCWB design criterion leads to a slight reduction in collapse probability for low-rise (2- and 4-storied) buildings, while it causes a significant reduction in collapse probability for mid-rise (8-storied) buildings. Further, this reduction in collapse probability is more pronounced in seismic zone $\mathrm{V}$ as compared to seismic zone IV.

FEMA P695 (2009) suggests a limit of 10\% probability of collapse conditioned on the occurrence of the MCE hazard level for a group of buildings, and $20 \%$ for individual buildings. The values shown in bold in Table 6 represent the failure of the corresponding buildings based on the FEMA P695 dual criterion. The average collapse probability for buildings non-conforming to the SCWB design criterion is found out to be $16 \%$, which reduces to $6 \%$ for buildings conforming to the SCWB design criterion. However, the 8-storey building in seismic zone V, even with SCWB design, passes the individual criterion of $20 \%$ probability of collapse (Table 6 ) only marginally.

\section{Conclusions}

IDA are conducted on a set of reinforced-concrete momentresisting frame buildings both non-conforming and conforming to the SCWB design requirements of Indian Standards. The effect of the SCWB design requirements on the

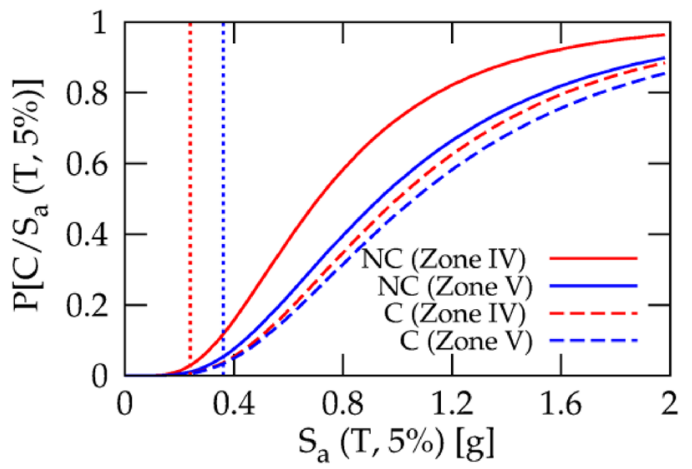

(a)

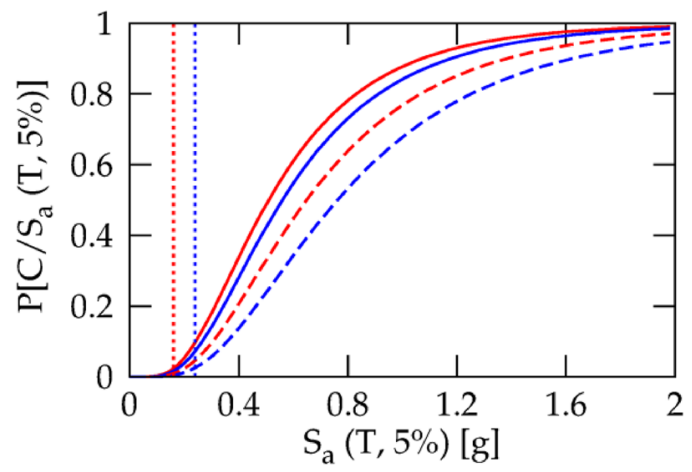

(b)

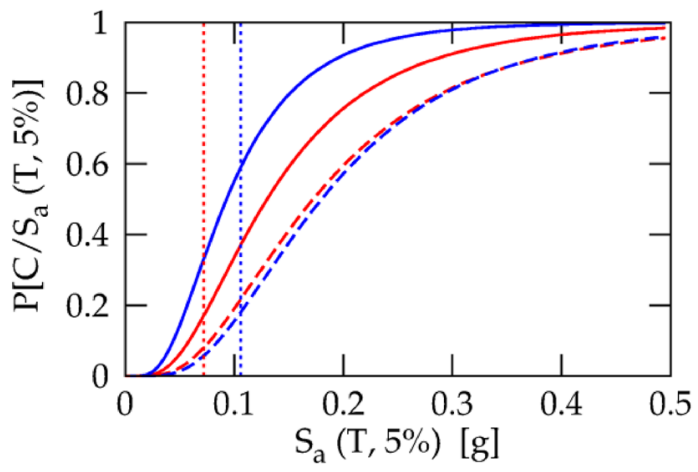

(c)

Fig. 6 Collapse fragility curves for the considered building models: a 2-storey buildings, b 4-storey buildings, and c 8-storey buildings. (the two vertical lines represent the spectral acceleration demands corresponding to the MCE hazard level for seismic zones IV and V, respectively)

governing collapse mechanism, collapse margin ratio and collapse fragility is investigated in detail.

Although, the conforming as well as non-conforming buildings were designed for identical base shear coefficients, the non-conforming buildings exhibit a significantly reduced collapse capacity as compared to the conforming buildings. This highlights the effect of collapse mechanism on seismic collapse capacity of buildings. It has been observed that the collapse mechanism strongly depends on the SCWB ratio 
Table 6 Collapse probability conditioned on the occurrence of MCE hazard for the considered building models

\begin{tabular}{lrl}
\hline Building model & $\mathrm{P}\left(\mathrm{C} / S_{\text {a MCE }}\right)(\%)$ & $\begin{array}{l}\text { Average col- } \\
\text { lapse probabil- } \\
\text { ity }(\%)\end{array}$ \\
\hline 2IVNC & 3 & $\mathbf{1 6}$ \\
4IVNC & 3 & \\
8IVNC & 17 & \\
2VNC & 5 & \\
4VNC & 7 & \\
8VNC & $\mathbf{6 0}$ & \\
2IVC & 1 & \\
4IVC & 1 & \\
8IVC & 8 & \\
2VC & 2 & \\
$4 \mathrm{VC}$ & 3 & \\
$8 \mathrm{VC}$ & 19 & \\
\hline
\end{tabular}

The values shown in bold indicate failure according to FEMA P695 acceptance criterion

used for the seismic design. Buildings non-conforming to the SCWB design criterion exclusively attract column failure mechanism, whereas buildings conforming to the SCWB design criterion show beam failure mechanism. Interestingly, the column yielding could not be avoided, even in buildings designed for a SCWB ratio of 1.4. However, in these buildings, failure of beams in a single (in case of low-rise buildings) or in multiple storeys (three storeys in the case of the studied 8-storey buildings) governed the collapse of the buildings.

The fragility analysis of the building models suggests that buildings non-conforming to the SCWB design criterion lead to unacceptably high probabilities of collapse (up to $60 \%$ in the case of mid-rise buildings) for the MCE hazard level. This performance improves significantly for buildings conforming to the SCWB criterion. Although, the 8-storey building designed for seismic zone $\mathrm{V}$ and conforming to the SCWB design requirements of Indian Standards, only marginally passes the FEMA P695 criterion of 20\% probability of collapse conditioned on the occurrence of MCE hazard for an individual building. Nevertheless, the group performance of the buildings conforming to the SCWB criterion is found out to be satisfactory.

The observed collapse mechanisms for the investigated building models suggest that there is still a possibility of improvement in the capacity design procedure to enhance the collapse performance of RC frame buildings. However, such improvements appear to be possible only by using variable SCWB ratios along the height of the building, so that failure of beams at all storeys is involved, while this topic may be the subject of future investigations. The present study is conducted with a limited number of structural models and plan shapes. The observations and conclusions drawn are limited to the considered suite of RC SMRF buildings of certain heights. Further, the ground-motion record suite used in the present study exclusively consists of far-field records. Near-field ground-motion records may certainly have significantly different characteristics as compared to far-field records. Therefore, separate studies are recommended to study the effect of near-field earthquakes on the governing collapse mechanism and collapse fragility.

Acknowledgements The first author's fellowships granted by the Ministry of Human Resource Development, Government of India and the Royal Norwegian Embassy to India (New Delhi) allowed the conduct of the present study. Parts of the investigations were carried out under the Indo-Norwegian collaboration project EQRisk. The support received from both agencies is gratefully acknowledged.

Open Access This article is distributed under the terms of the Creative Commons Attribution 4.0 International License (http://creativeco mmons.org/licenses/by/4.0/), which permits unrestricted use, distribution, and reproduction in any medium, provided you give appropriate credit to the original author(s) and the source, provide a link to the Creative Commons license, and indicate if changes were made.

\section{References}

ACI (2014) Building code requirements for structural concrete and commentary, ACI 318-14. American Concrete Institute, Framington Hills

ASCE (2010) Minimum design loads for buildings and other structures, ASCE Standard, ASCE 7-10. American Society of Civil Engineers, Reston

ASCE (2013) Seismic evaluation and retrofit of existing buildings, ASCE Standard, ASCE/SEI 41-13. American Society of Civil Engineers, Reston

Cagurangan CK (2015) Effects of strong column weak beam ratios on collapse capacities of tall reinforced concrete moment frame structures. Ph.D. Thesis, University of California, Berkeley

CSI (2016) ETABS 2016 Integrated Building Design Software, Version 16.0.2. Computers and Structures, Inc., Berkeley

Dadi SK, Agarwal P (2015) Effect of types of reinforcement on plastic hinge rotation parameters of RC beams under pushover and cyclic loading. Earthq Eng Eng Vib 14:503-516

DEQ (2009) Seismic vulnerability of multistory buildings in Noida. Technical Report, Department of Earthquake Engineering, Indian Institute of Technology Roorkee, Roorkee, pp 1-118

Dooley KL, Bracci JM (2001) Seismic evaluation of column to beam strength ratio in reinforced concrete frames. ACI Struct J 98:843-851

Eurocode 8 (2004) Design of structures for earthquake resistance- part 1: general rules, seismic actions and rules for buildings. European Committee for Standardization, Brussels

Farsangi EN, Tasnimi AA (2016) The influence of horizontal and vertical coupled ground excitations on the collapse margins of modern RC MRF's. Int J Adv Struct Eng 8:169-192

FEMA (2009) Quantification of building seismic performance factors. FEMA P695, Federal Emergency Management Agency, Washington, DC 
FEMA (2012) Seismic performance assessment of buildings—volume 1 methodology. FEMA P58, Federal Emergency Management Agency, Washington, DC

Haldar P (2013) Seismic behaviour and vulnerability of Indian RC frame buildings with URM infills, Ph.D. Thesis, Indian Institute of Technology, Roorkee, Roorkee

Haselton CB and Deierlein GG (2007) Assessing seismic collapse safety of modern reinforced concrete frame buildings. PEER Report 2007/08, PEER Center, University of California, Berkeley

Haselton CB, Liel AB, Taylor Lange S and Deierlein GG (2007) Beam column element model calibrated for predicting flexural response leading to global collapse of RC frame buildings. PEER Report 2007/03, PEER Center, University of California, Berkeley

Haselton CB, Liel AB, Deierlein GG, Dean BS, Chou JH (2011) Seismic collapse safety of reinforced concrete buildings. I: assessment of ductile moment frames. J Struct Eng ASCE 137:481-491

Ibarra LF and Krawinkler H (2005) Global collapse of frame structures under seismic excitations. John A. Blume Earthquake Engineering Center, PEER Report 2005/06, September 2005, Department of Civil and Environmental Engineering, Stanford University

IS 13920 (1993) Ductile detailing of reinforced concrete structures subjected to seismic forces-code of practice. Bureau of Indian Standards, New Delhi

IS 13920 (2016) Ductile design and detailing of reinforced concrete structures subjected to seismic forces-code of practice. Bureau of Indian Standards, New Delhi

IS 1893 Part 1 (2002) Indian standard criteria for earthquake resistant design of structures, part 1: general provisions and buildings (fifth revision). Bureau of Indian Standards, New Delhi

IS 1893 Part 1 (2016) Indian standard criteria for earthquake resistant design of structures, part 1: general provisions and buildings (sixth revision). Bureau of Indian Standards, New Delhi

IS 456 (2000) Indian standard-plain and reinforced concrete, code of practice. Bureau of Indian Standards, New Delhi

IS 875 (Part 1) (1987a) Indian standard - code of practice for design loads (other than earthquake) for buildings and structures (dead loads). Bureau of Indian Standards, New Delhi

IS 875 (Part 2) (1987b) Indian standard - code of practice for design loads (other than earthquake) for buildings and structures (live loads). Bureau of Indian Standards, New Delhi

Kazemi H, Ghafory Ashtiany M, Azarbakht A (2013) Effect of epsilon based record selection on fragility curves of typical irregular steel frames with concrete shear walls in Mashhad City. Int J Adv Struct Eng 5:1-11

Kuntz GL, Browning J (2003) Reduction of column yielding during earthquakes for reinforced concrete frames. ACI Struct J 100:573-580

LATBSDC (2014) An alternative procedure for seismic analysis and design of tall buildings located in the Los Angeles region. Los Angeles Tall Building Seismic Design Council, Los Angeles

Liel AB, Haselton CB, Deierlein GG, Baker JW (2009) Incorporating modelling uncertainties in the assessment of seismic collapse risk of buildings. Struct Saf 31:197-211

Moniri H (2017) Evaluation of seismic performance of reinforced concrete buildings under near-field earthquakes. Int J Adv Struct Eng 9:13-25

NIST (2012) Tentative framework for development of advanced seismic design criteria for new buildings, NIST GCR 12-917-20. Natl Inst Stand Technol, Gaithersburg

PEER/ATC-72-1 (2010) Modelling and acceptance criteria for seismic design and analysis of tall buildings. Applied Technology Council, Redwood City

Shakib H, Pirizadeh M (2014) Probabilistic seismic performance assessment of setback buildings under bidirectional excitation. J Struct Eng ASCE 140:1736-1745

Standards New Zealand (NZS 3101) (2006) Concrete structures standard, Wellington

Surana M, Singh Y, Lang DH (2018a) Floor spectra of inelastic RC buildings considering ground-motion characteristics. J Earthq Eng 22:488-519

Surana M, Singh Y, Lang DH (2018b) Seismic characterization and vulnerability of building stock in hilly regions. Nat Hazards Rev ASCE. https://doi.org/10.1061/(ASCE)NH.1527-6996.0000275

Vamvatsikos D, Cornell CA (2002) Incremental dynamic analysis. Earthq Eng Struct Dyn 31:491-514

Publisher's Note Springer Nature remains neutral with regard to jurisdictional claims in published maps and institutional affiliations. 